\title{
La investigación clínica como generadora de conocimiento científico
}

\section{Clinical research as a source of scientific knowledge}

Llevamos más de 250 años investigando. Ya en 1747, el médico escocés James Lind comenzó lo que se considera que es el primer ensayo clínico de la historia. Lind a bordo del buque Salisbury, trató a doce marineros enfermos de escorbuto con diferentes dietas y observó que dos de ellos que consumían naranja y limón mejoraron rápidamente: Este estudio tenía su origen en la pregunta ¿cuál era la causa del escorbuto?. Y así aparecían las respuestas.

Hoy más que nunca podemos decir que la investigación es protagonista de soluciones claras y concretas para un mundo mejor, no caben dudas que los Ensayos Clínicos controlados ayudan a salvar vidas porque revisan huellas para encontrar verdades.

La palabra investigación proviene de la voz latina "vestigium", que significa ir tras la pista, y que puede ser explicada como una forma de mostrar la realidad para indagar, cuestionar o interpretarla.

La prueba de ello es analizar hoy ¿qué nos pasó con esta pandemia?, y encontramos finalmente que la investigación es la única que nos está entregando respuestas. Quién, sino el conocimiento científico, nos cuestionó hasta como sociedad, que no nos sirve de nada insistir en que somos diferentes por tener distintas razas, credos, ocupación, condición social o nacionalidad. Todos podemos enfermar.

En esta pandemia sólo la investigación es la generadora del conocimiento científico para que podamos responder estos grandes cuestionamientos que enfrenta hoy la humanidad: ¿qué tipo de virus es COVID 19? ¿cómo llego al hombre?, ¿porque la afinidad por ciertos órganos? ¿Infecta o inflama? ¿quiénes son los pacientes de riesgo? ¿qué medicamento es el más efectivo? ¿cómo mejorar la letalidad? ¿sirve el plasma de pacientes convalecientes? ¿y la vacuna? ¿Cuándo tendremos una efectiva y segura? Y más y más preguntas nos surgen cada día.

En la actualidad un paciente infectado de COVID 19, sabe que hay protocolos de tratamientos, algunos ya estandarizados y otros en investigación hasta llamados Solidaridad por la OMS. Actualmente la comunidad entera habla de las "fases de investigación" que debe atravesar un Ensayo Clínico de una

Revista Methodo: Investigación Aplicada a las Ciencias Biológicas. Facultad de Medicina. Universidad Católica de Córdoba. Jacinto Ríos 571 Bo Gral. Paz. X5004FXS. Córdoba. Argentina. Tel.: (54) 3514517299 / Correo: methodo@ucc.edu.ar / Web: methodo.ucc.edu.ar | EDITORIAL Rev. Methodo 2020;5(4):127-128. 
vacuna para llegar a ser usada en la población y que son muchas las vacunas que están en carrera por lograr ser la mejor opción de prevención.

La comunidad médica sabe que la información que viene de la investigación se transformará en nuevos conocimientos, favoreciendo así el desarrollo de la salud.

En esta nueva crisis donde tiembla el suelo del mundo entero, lo más estable es la investigación.

Investigar es ir más allá de lo que se ve, es analizar, revisar, comparar, evaluar, reconocer, es convertir datos en conocimientos. El objetivo de la Investigación Clínica es la búsqueda de la evidencia y estas son las bases para establecer guías, que vuelven a la comunidad en mejoras de salud tanto en prevención como en tratamientos.

Sin investigación, no hay salud, pero sin principios éticos no hay investigación aceptable. Con el orden y la rigurosidad de siempre, solo la investigación nos brinda los pasos firmes para avanzar en este mundo lleno de viejas y nuevas inquietudes e incertidumbres.

La Investigación Clínica como generadora de conocimiento científico exige mucha dedicación, esfuerzo y un gran espíritu científico, pero también requiere de una legislación que la regule y de un control estatal que la transparente.

¿Será que esta pandemia nos está dejando una revalorización de la investigación clínica? Presiento un sereno SI.

Todos tienen interrogantes, la investigación tiene las respuestas.

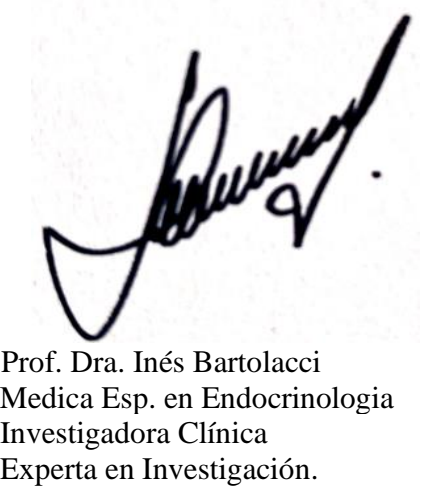

Bibliografía.

1 Tröhler U. 'To improve the evidence of medicine. The 18th century British origins of a critical approach.' Edinburgh: Royal College of Physicians, 2000: 59-68

2 https://www.who.int/es/emergencies/diseases/novel-coronavirus-2019/global-research-on-novel-coronavirus-2019-ncov/solidarityclinical-trial-for-covid-19-treatments.

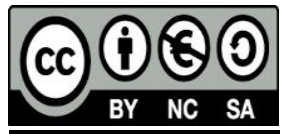

Revista Methodo: Investigación Aplicada a las Ciencias Biológicas. Facultad de Medicina. Universidad Católica de Córdoba. Jacinto Ríos 571 Bo Gral. Paz. X5004FXS. Córdoba. Argentina. Tel.: (54) 3514517299 / Correo: methodo@ucc.edu.ar / Web: methodo.ucc.edu.ar | EDITORIAL Rev. Methodo 2020;5(4):127-128. 